\title{
Crystal violet staining to quantify Candida adhesion to epithelial cells
}

M. NEGRI, V. GONÇALVES, S. SILVA, M. HENRIQUES, J. AZEREDO and R. OLIVEIRA

Institute for Biotechnology and Bioengineering (IBB), Centre of Biological Engineering, Universidade do Minho, Braga, Portugal

Accepted: 22 March 2010

\section{Introduction}

Candida species can adhere to a variety of different surfaces in the human body, thus facilitating the colonisation of many host niches. Remarkably, such niches provide very different environments for growth, and Candida has developed specific mechanisms to adapt to the respective conditions. Several studies have shown a correlation between adhesion of organisms and their potential virulence. ${ }^{1-4}$

Adhesion to epithelial cells is well recognised as an essential step in the process of Candida colonisation and subsequent infection. ${ }^{5}$ Candida adhesion to epithelial cells has been investigated to define parameters relevant to the pathogenesis of oral, gastrointestinal, vaginal and urinary candidiasis. ${ }^{6}$ Furthermore, Candida can also grow on abiotic surfaces (e.g., plastic devices), for example, leading to biofilm formation in catheters, which represents a major problem especially in intensive care units. ${ }^{2,7}$

Over the past decades, a broad range of model systems have been described for the in vitro study of Candida adhesion to hard surfaces. ${ }^{8}$ In most model systems, quantification of yeast cells is obtained by plating, which is labour-intensive and slow. ${ }^{9}$ Moreover, yeast adhesion to epithelium can be determined by visual methods (e.g., light, fluorescence, scanning or transmission electron microscopy) or by counting radiolabelled yeast. ${ }^{6}$

The visual method involves incubating standard yeast suspensions with confluent cell monolayers grown on a coverslip. Following removal of unattached yeasts, the number of adherent organisms per unit area of the monolayer is determined by direct microscopy after air drying, Gram staining and mounting on glass slides. Although visualisation allows monitoring of adhesion to individual epithelial cells, it is a very time-consuming technique. ${ }^{10,11}$ The radiolabelling method seems to offer an attractive alternative in some situations, although leaching of the isotope can produce misleading results. ${ }^{6}$

Crystal violet (CV) staining, which is commonly used for the indirect quantification of adherent cells and amount of

Correspondence to: Mariana Henriques

Department of Biological Engineering, Universidade do Minho,

Campus de Gualtar 4710-057, Braga, Portugal

Email:morh@deb.uminho.pt

\section{ABSTRACT}

In vitro studies of adhesion capability are essential to characterise the virulence of Candida species. However, the assessment of adhesion by traditional methods is timeconsuming. The aim of the present study is the development of a simple methodology using crystal violet staining to quantify in vitro adhesion of different Candida species to epithelial cells. The experiments are performed using Candida albicans (ATCC 90028), C. glabrata (ATCC 2001), C. parapsilosis (ATCC 22019) and C. tropicalis (ATCC 750). A human urinary bladder epithelial cell line (TCC-SUP) is used. Yeast and epithelial cells were stained with crystal violet, epithelial cells were then destained using intermediate washing, and the dye in the yeast cells was extracted with acetic acid. The method was validated for the different Candida reference species by comparison with traditional microscope observation and enumeration. The method was then used to assess Candida adhesion to epithelial cells and also to silicone. For all Candida spp. high correlation values $\left(r^{2}=0.9724-0.9997\right)$ between the number of adherent yeasts (microscope enumeration) and absorbance values were obtained for an inoculum concentration $>10^{6}$ cells $/ \mathrm{mL}$. The proposed technique was easy to perform and reproducible, enabling the determination of adhesion ability of Candida species to an epithelial cell line.

\section{KEY WORDS: Adhesion. \\ Candida. \\ Cell line. \\ Epithelial cells. \\ Gentian violet. \\ Silicones.}

biofilm formed by Candida on abiotic surfaces, is a quick and cheap method. It involves a basic dye, which binds to negatively charged surface molecules and polysaccharides in the extracellular matrix ${ }^{8,12}$ and dissolves easily in acetic acid.

The aim of this study is to develop a quick and simple technique to assess the number of Candida adherent to epithelial cells, based on the quantification of crystal violet absorbance.

\section{Materials and methods}

\section{Yeasts and growth conditions}

Candida species used in this study were Candida albicans (ATCC 90028), C. glabrata (ATCC 2001), C. parapsilosis (ATCC 22019) and C. tropicalis (ATCC 750), obtained from the American Type Culture Collection. Strains were kept frozen 
at $-80^{\circ} \mathrm{C}$ in Sabouraud dextrose broth (SDB; Liofilchem, Italy) containing 5\% (v/v) glycerol. Candida spp. were subcultured on Sabouraud dextrose agar (SDA; Liofilchem, Italy) for $24 \mathrm{~h}$ and then grown in SDB for $18 \mathrm{~h}$ at $37^{\circ} \mathrm{C}$ at $120 \mathrm{rpm}$. After incubation, yeasts were harvested at $8000 \mathrm{rpm}$ for $5 \mathrm{~min}$. Cells resuspended in phosphate-buffered saline (PBS, $0.01 \mathrm{~mol} / \mathrm{L}, \mathrm{pH}$ 7.5) were enumerated using a haemocytometer (Boeco, Germany) and the final concentration (specific to each assay) was adjusted with PBS.

\section{Epithelial cells}

A human urinary bladder epithelial cell line (TCC-SUP; DSMZ - German Collection of Microorganisms and Cell Cultures) was used. Cells were cultured at $37^{\circ} \mathrm{C}$ in $5 \% \mathrm{CO}_{2}$ in Dulbecco's modified Eagle's medium (DMEM; Gibco, USA) containing $15 \%$ fetal bovine serum (FBS; Gibco, USA) and $1 \%$ penicillin/streptomycin (P/S; Gibco, USA) in cell culture flasks. After achieving $80 \%$ confluence, cells were detached using a 25\% trypsin-EDTA solution (Gibco, USA) and cell concentration was adjusted to $1 \times 10^{6}$ cells $/ \mathrm{mL}$ with fresh DMEM without $\mathrm{P} / \mathrm{S}$ and added to each well of a sixwell plate. Wells were washed (x2) with PBS prior to assay.

\section{Silicone}

Coupons $(2 \times 2 \mathrm{~cm})$ were cut from a $1 \mathrm{~mm}$ layer of silicone (Neves e Neves, Trofa, Portugal). All coupons were cleaned by immersion in ultrapure water for $2 \mathrm{~h}$, followed by immersion in ethanol $50 \%(\mathrm{v} / \mathrm{v})$ for $4 \mathrm{~h}$. After rinsing with ultrapure water and air-drying, the coupons were autoclaved for $15 \mathrm{~min}$ at $121^{\circ} \mathrm{C}$.

\section{Adhesion assay}

Yeast cells were suspended in PBS to final concentrations of $10^{4}, 10^{5}, 10^{6}, 10^{7}$ and $10^{8}$ yeast $/ \mathrm{mL}$. Then, $3 \mathrm{~mL}$ each cell suspension was added to each well of the plate for tissue culture containing either a confluent layer of epithelial cells or the silicone coupon. After incubation $\left(2 \mathrm{~h}, 120 \mathrm{rpm}, 37^{\circ} \mathrm{C}\right)$ the wells were washed $(\mathrm{x} 2)$ with PBS to remove unattached yeasts. Yeast cells were quantified using the CV staining method and also light microscope observation. All procedures were repeated in triplicate in three separate assays.

\section{Crystal violet assay}

Crystal violet $(3 \mathrm{~mL}, 1 \%[\mathrm{w} / \mathrm{v}]$ in water) was added to each well containing the epithelial cells with adherent yeasts and allowed to stain for $5 \mathrm{~min}$. The wells were then washed (x3) with PBS. To remove CV from the epithelial cells, $3 \mathrm{~mL}$ ethanol:acetone (1:1) was added to the wells and removed immediately. Acetic acid (33\%, $3 \mathrm{~mL})$ was added to each well and absorbance was read at $570 \mathrm{~nm}$. Wells containing epithelial cells without yeasts were used as controls. Mean absorbance of yeasts was expressed as absorbance per area of each well.

Candida adherent to silicone were quantified according to the method of Henriques et al. ${ }^{13}$ Briefly, the coupons containing adherent yeasts were removed from each well and immersed for $5 \mathrm{~min}$ in a new well plate containing $3 \mathrm{~mL}$ methanol. After discarding the methanol, the coupons were allowed to dry at room temperature. Crystal violet $(3 \mathrm{~mL})$ was added to each well and allowed to stain for $5 \mathrm{~min}$. Coupons were then removed to a new well, washed with ultrapure water and immersed in $3 \mathrm{~mL}$ acetic acid (33\%) to dissolve the stain. Coupons without yeasts were used as
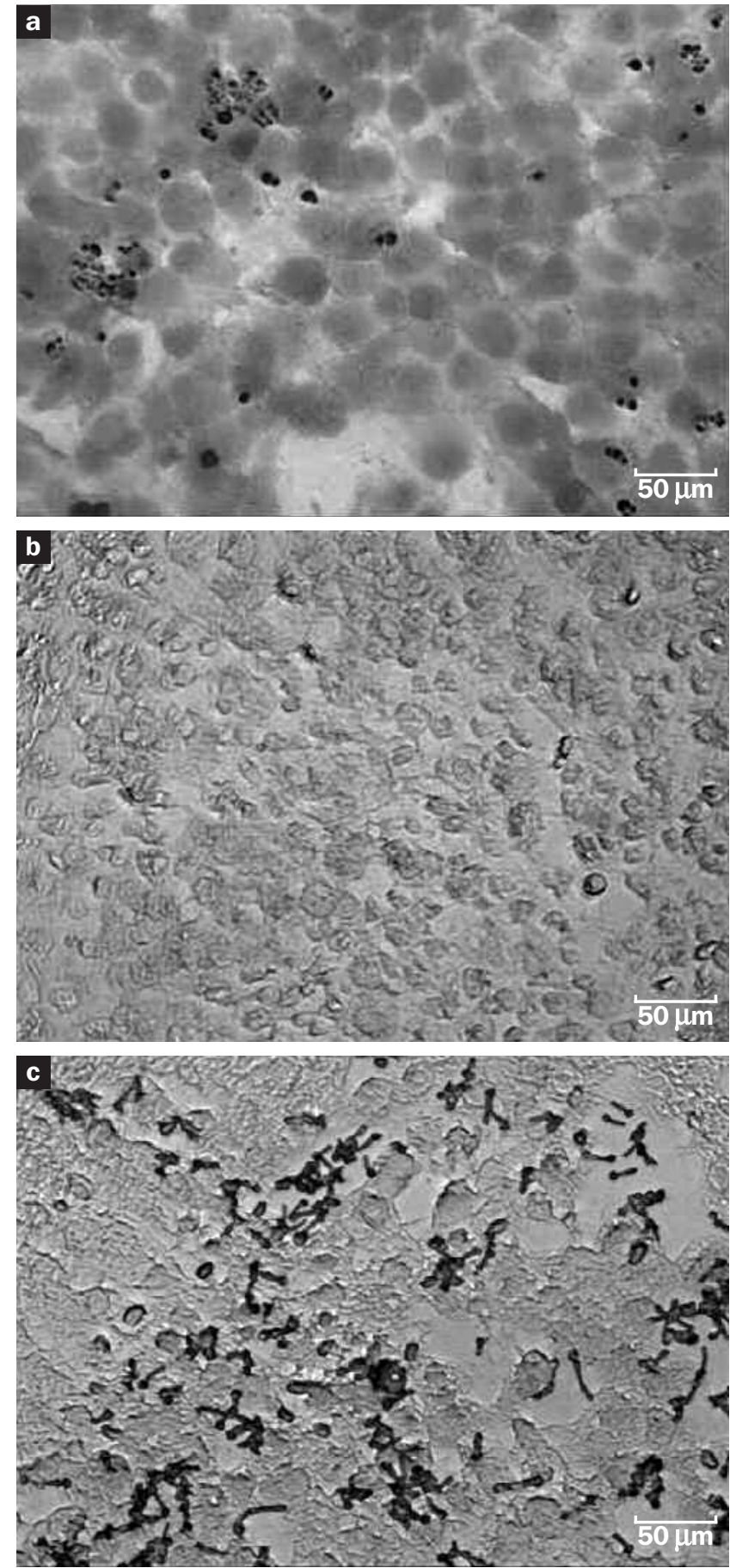

Fig. 1. Phase contrast images of the steps of the proposed method: a) yeasts and TCC-SUP cells stained with CV only; b) TCC-SUP cells destained with ethanol and acetone; c) Yeast cells stained strongly with crystal violet and TCC-SUP cells destained with ethanol and acetone (original magnification x200).

controls. Absorbance of the resultant acetic acid solution was read at $570 \mathrm{~nm}$. Mean absorbance of yeasts was expressed as absorbance per unit area of the coupon.

\section{Microscope observation}

Epithelial cells and coupons with adherent yeasts were treated as described above, but without acetic acid. A duplicate of each plate was performed. Candida attached to TCC-SUP were quantified using an inverted light 
microscope (Nikon Diaphot, x 400 magnification). Ten fields were randomly observed in each well. As the samples were set up in triplicate for each experiment, the mean number of yeasts per 30 fields was expressed as number of cells per unit area of the well. Candida cells with small daughter cells were regarded as one cell.

\section{Statistical analysis}

Results obtained were analysed using the SPSS (Statistical Package for the Social Sciences) program. One-way ANOVA with Bonferroni test was used to compare the number of adherent cells of the four strains. $P<0.05$ was considered significant.

\section{Results}

The method proposed in this study involves CV staining of Candida adherent to an epithelial cell monolayer. As cells, yeasts and epithelium are all stained with CV (Fig. 1A) it was necessary to develop a technique (using a mixture of ethanol/acetone) that permitted the removal of CV from epithelial cells (Fig. 1B), allowing it to remain in the Candida cells (Fig. 1C). It was then possible, using acetic acid, to remove $\mathrm{CV}$ from the Candida and read the absorbance of the solution obtained.

After the confirmation, by microscopy, of the applicability of this method, it was necessary to validate the technique by assessing and comparing adhesion using traditional enumeration of adherent yeast cell by microscope observation. The relationship between $\mathrm{CV}$ absorbance and the number of Candida attached to epithelial cells is presented in Figure 2. The values obtained were $r^{2}=0.9995$ for C. albicans, $r^{2}=0.9997$ for C. tropicalis, $r^{2}=0.9724$ for C. glabrata and $r^{2}=0.9997$ for C. parapsilosis.

The method proved adequate for the detection of Candida attachment at high yeast numbers, specifically above $1 \times 10^{5} \mathrm{cell} / \mathrm{cm}^{2}$ for C. albicans (Fig. $2 \mathrm{~A}$ ), $2 \times 10^{5} \mathrm{cell} / \mathrm{cm}^{2}$ for C. tropicalis (Fig. 2B), $3 \times 10^{4}$ cell $/ \mathrm{cm}^{2}$ for C. glabrata (Fig. 2C) and $1 \times 10^{4} \mathrm{cell} / \mathrm{cm}^{2}$ for $C$. parapsilosis (Fig 2D).

Different Candida species have different sizes and absorb distinct amounts of dye, which does not allow comparison of the level of adhesion through direct CV absorbance readings. However, standardisation of the results is possible using respective equation curves for each species.

After the implementation of the methodology, the extent of adhesion of the different Candida spp. to TCC-SUP epithelial cells and also to silicone was determined (Fig. 3). As shown in Figure 3A, there were significant differences in the number of yeasts adherent to epithelial cells among the different concentrations tested for each Candida sp., except for C. parapsilosis. On silicone, the differences were significant for all C. albicans and C. parapsilosis inocula concentrations but only for the highest values in C. glabrata a

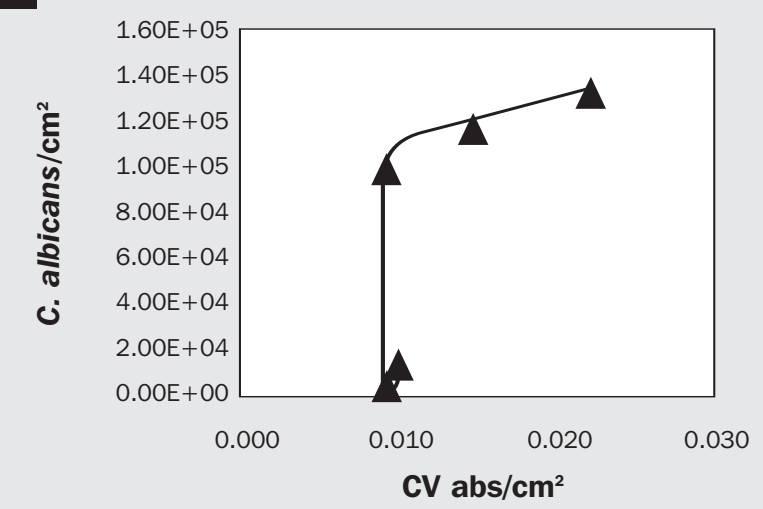

c

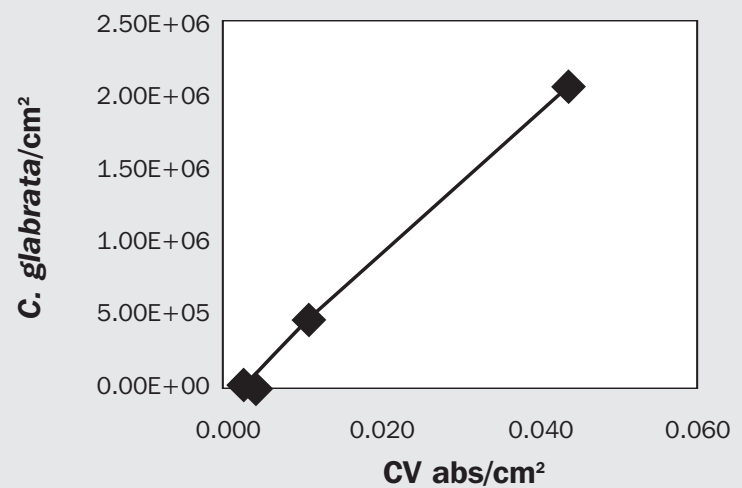

b

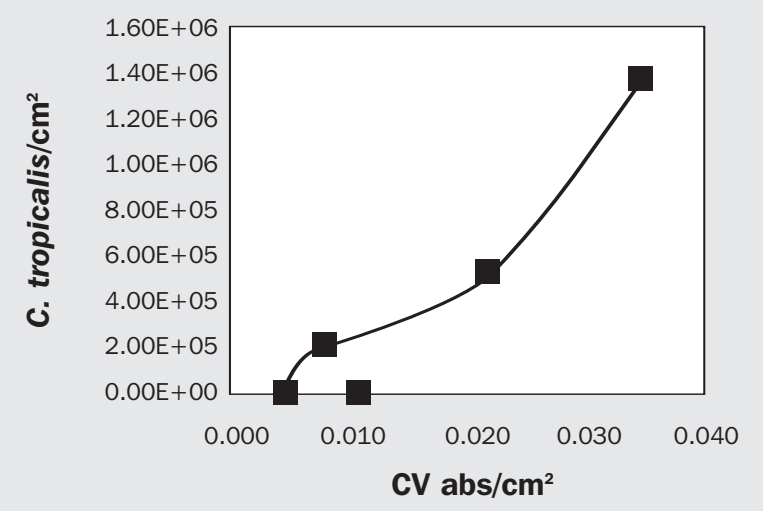

d

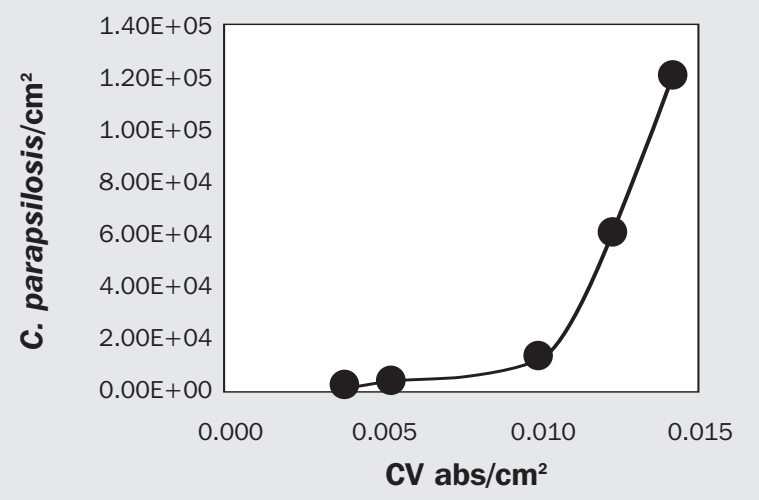

Fig. 2. Relationship between the number of a) Candida albicans, b) C. tropicalis, c) C. glabrata and d) C. parapsilosis adherent to TCC-SUP epithelial cells, and the corresponding CV absorbance (CV abs) at $570 \mathrm{~nm}$. The adherent Candida spp. were expressed as yeast number or CV absorbance per area of each well. All procedures were performed in triplicate in three separate assays 
a

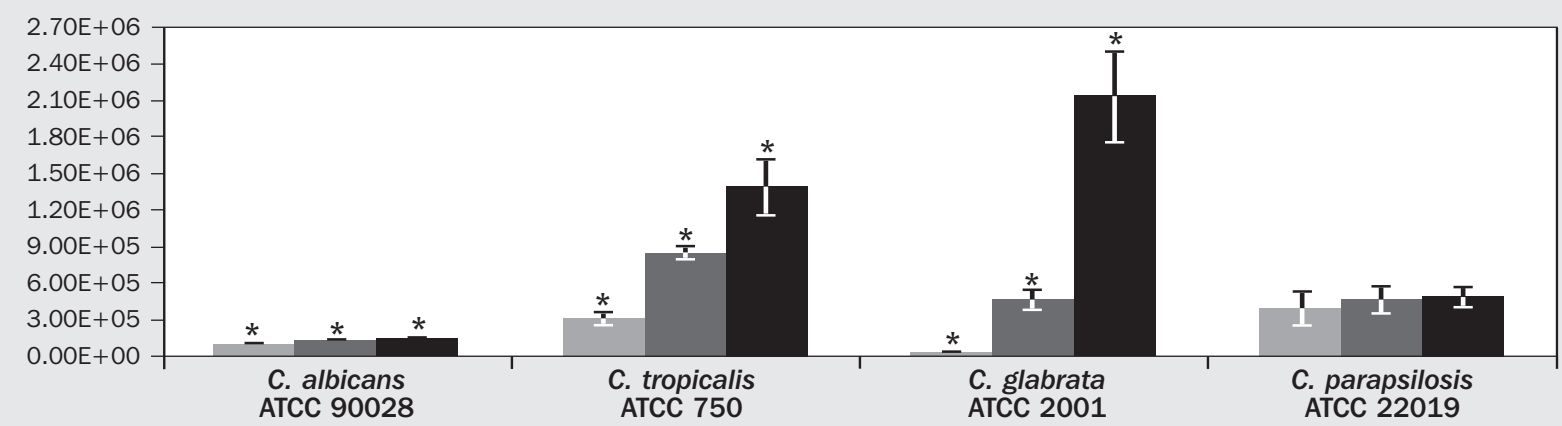

b

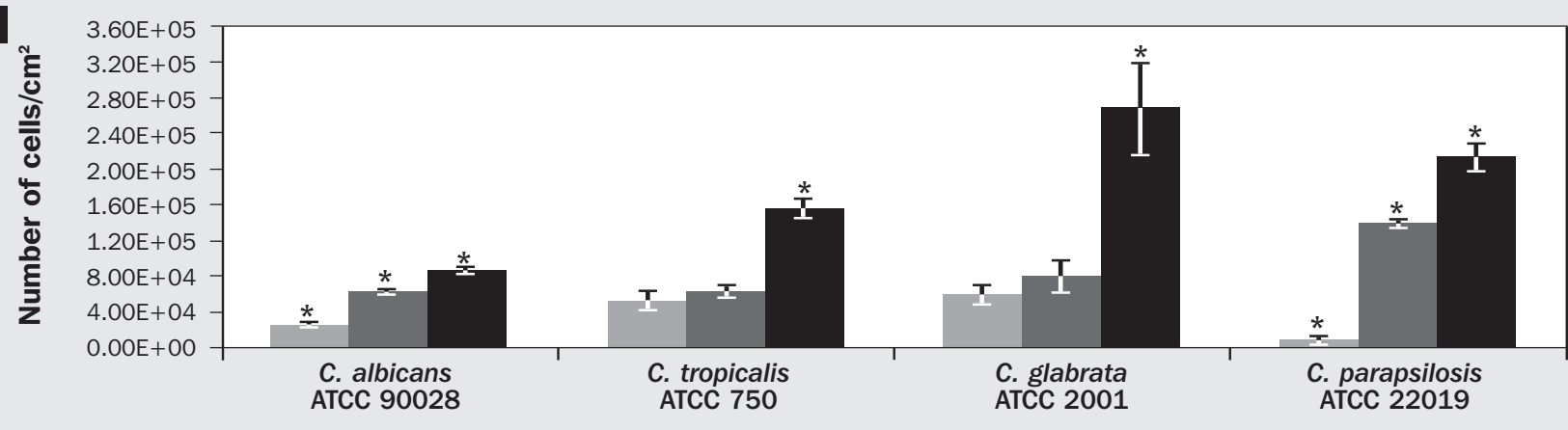

Fig. 3. Candida spp. cells adherent to a) TCC-SUP epithelial cells and b) silicone measured by crystal violet absorbance reported as cell/ $\mathrm{cm}^{2}$. Data are the average of three measurements (+SD). The initial cell density: $10^{6}(\square), 10^{7}(\square)$ and $10^{8}$ cell/mL $(\square)$. ${ }^{*} P<0.05$ between the different inoculums for the same species.

and C. tropicalis (Fig. 3B). All Candida species adhered to a greater extent to epithelial cells than to silicone.

Considering the difference between species, it is possible to observe (Fig. 3) that $C$. glabrata $(P<0.05)$ adhered significantly more than other Candida spp. (initial cell density: $10^{7}$ and $10^{8}$ yeast $/ \mathrm{mL}$ ) to epithelial cells, and C. tropicalis (initial cell density: $10^{6}$ and $10^{7}$ yeast $/ \mathrm{mL} ; P<0.05$ ) to silicone. $C$. albicans adhered less than other yeasts to both surfaces at $10^{8}$ yeasts $/ \mathrm{mL}(P<0.05)$.

The methodology proposed proved efficient in demonstrating the in vitro adherence of $C$. albicans (ATCC 90028), C. glabrata (ATCC 2001), C. parapsilosis (ATCC 22019) and C. tropicalis (ATCC 750) to TCC-SUP.

\section{Discussion}

Most Candida infections are associated with adhesion to implanted medical devices or to host epithelial cell surfaces. ${ }^{14}$ In vitro adherence studies of Candida on different surfaces are well established. ${ }^{3,4,8,10,15}$ One quantification method is direct enumeration by microscopy, which has been used widely to determine the extent of yeast adhesion to epithelial cells. ${ }^{16}$ Although this technique permits visualisation of the yeast cells adherent to individual epithelial cells, it is very time-consuming. ${ }^{11}$ Other techniques described to evaluate Candida adhesion to biological and inert surfaces include indirect immunofluorescence, ${ }^{17}$ fluorescence-labelled cytometry, ${ }^{18}$ radioisotope analysis ${ }^{19}$ and photometric quantification..$^{20}$ However, most of these do not balance accuracy, speed, reproducibility and costeffectiveness. $^{6}$

The method described here is based on CV staining to quantify microbial adhesion and biofilm formation on inert surfaces. ${ }^{13,21}$ However, the application of this method to assess adhesion to epithelial cells is not straightforward as both epithelial and yeast cells absorb CV dye (Fig. 1A). It is possible to circumvent this problem by using a mixture of ethanol/acetone to remove the stain from the epithelial cells (Fig. 1B) but not the Candida cells (Fig. 1C).

Figure 2 shows that it is possible to establish a direct relationship between the number of Candida adherent to TCC-SUP cells and CV absorbance, and were obtained for initial inocula concentrations of $10^{6}, 10^{7}$ and $10^{8}$ yeast $/ \mathrm{mL}$. According to Henriques et al. ${ }^{11}$ there is no detectable yeast attachment at concentrations below $10^{4}$ yeast $/ \mathrm{mL}$, and $10^{7}$ yeast $/ \mathrm{mL}$ is the most frequently used Candida inoculum concentration. ${ }^{16,22}$ The high correlation between $\mathrm{CV}$ absorbance values and the number of Candida cells obtained by microscopy confirms the utility of determining attached cell numbers through the corresponding absorbance reading.

The extent of adhesion of C. albicans 90028, C. glabrata 2001, C. parapsilosis 22019 and C. tropicalis 750 to TCC-SUP cells and to silicone was also determined using the proposed method (Fig. 3). As Candida spp. differ on size, their absorbance value was standardised (according to each species curve) in order to permit comparison. It was noticed that different inoculum concentrations gave significantly different $(P<0.05)$ numbers of Candida adherent to the epithelial cells; an observation made by others ${ }^{23-25}$ who report that the attachment of Candida species to epithelial cells gradually increases as the ratio of yeasts to epithelial cells, in incubation mixtures, is raised from 10:1 to 10000:1.

Differences were detected in the adherence of Candida spp. to TCC-SUP cells and silicone. All Candida were more prone to adhere to TCC-SUP than to silicone (Fig. 3). Sohn et al. ${ }^{3}$ described the comparison of adhesion of C. albicans to the 
human colorectal carcinoma cell line Caco-2 and to epidermoid vulvovaginal A431 cells and to polystyrene, reporting that $C$. albicans adherence is high to polystyrene and both epithelia.

C. albicans and C. parapsilosis adhered to a similar extent on both surfaces at an initial concentration of $10^{8}$ cells $/ \mathrm{mL}$, but less than the other yeasts studied. Tamura et al ${ }^{26}$ investigated the adherence of C. albicans and C. parapsilosis to urinary catheters made of latex or silicone and found that adhesion of C. albicans was significantly greater than C. parapsilosis on latex, but similar on silicone. Furthermore, De Bernardis et al. ${ }^{1}$ observed that from all the non-C. albicans species (NCAC) studied, C. parapsilosis seemed to be the least virulent, which might be consistent with lower adherence to epithelial cells.

Owing to the increasing prevalence of NCAC species, especially in immunosuppressed patients, more insight about virulence factors associated with these species is required. However, relatively little is known about the mechanisms of NCAC adhesion to epithelium or about factors affecting the adhesion process. ${ }^{11} \mathrm{C}$. tropicalis is a common species related to nosocomial candidaemia and candiduria, and C. glabrata is now emerging as an important agent in both mucosal and bloodstream infections. ${ }^{14,27}$ Nevertheless, the adhesion mechanism of these species to different surfaces remains unclear. ${ }^{11,14}$

From Figure $3 \mathrm{~A}$, it is possible to see that C. glabrata $(P<0.05)$ adhered in greater numbers than did other yeasts (initial cell density: $10^{7}$ and $10^{8}$ cell $/ \mathrm{mL}$ ) to epithelial cells, and C. tropicalis $(P<0.05)$ adhered in considerable numbers to silicone (initial cell density: $10^{6}$ and $10^{7}$ cell $/ \mathrm{mL}$ ).

Strain differences were noted in the ability of C. glabrata to adhere to oral epithelial cells, synthesise phospholipases and trigger cytokine responses. ${ }^{28-30}$ According to Shin et al., ${ }^{31}$ biofilm occurred most frequently in isolates of $C$. tropicalis, followed by C. parapsilosis, C. glabrata and C. albicans. Virulence of $C$. tropicalis may be due to its greater adhesion to different surfaces and its ability to secrete moderate amounts of proteinase and filamentous forms compared to other NCAC species. ${ }^{14,19,32}$

In conclusion, the proposed methodology is both easy to execute and cheap, and is reproducible in assessing Candida adhesion to TCC-SUP cells. It is a valuable methodology to discriminate the adhesive capacity of different Candida spp. isolates to different epithelial cells, and may contribute to research on the virulence of C. albicans and NCAC species.

The authors acknowledge Cordenação de Aperfeiçoamento de Pessoal de Nivel Superior (CAPES), Brazil, for its support of MN through grant BEX 4642/06-6, and Fundação para a Ciência e Tecnologia (FCT) for its support of SS through grant SFRH/BD/28341/2006.

\section{References}

1 De Bernardis F, Mondello F, San Millàn R, Ponton J, Cassone A. Biotyping and virulence properties of skin isolates of Candida parapsilosis. J Clin Microbiol 1999; 37: 3481-6.

2 Douglas LJ. Candida biofilms and their role in infection. Trends Microbiol 2003; 11: 30-6.

3 Sohn K, Senyürek I, Fertey J et al. An in vitro assay to study the transcriptional response during adherence of Candida albicans to different human epithelia. FEMS Yeast Res 2006; 6: 1085-93.

4 Chassot F, Negri MF, Svidzinski AE et al. Can intrauterine contraceptive devices be a Candida albicans reservoir? Contraception 2008; 77: 355-9.

5 Lyman C A, Navarro E, Garrett KF, Roberts DD, Pizzo PA, Walsh TJ. Adherence of Candida albicans to bladder mucosa: development and application of a tissue explant assay. Mycoses 1999; 42: 255-9.

6 Ellepola ANB, Samaranayake LP. Investigative methods for studying the adhesion and cell surface hydrophobicity of Candida species: an overview. Microb Ecol Health Dis 2001; 13: 46-54.

7 Kumamoto CA. Candida biofilms. Curr Opin Microbiol 2002; 5: 608-11.

8 Peeters E, Nelis HJ, Coenye T. Comparison of multiple methods for quantification of microbial biofilms grown in microtiter plates. J Microbiol Methods 2008; 72: 157-65.

9 Donlan RM, Costerton JW. Biofilms: survival mechanisms of clinically relevant microorganisms. Clin Microbiol Rev 2002; 15: 167-93.

10 Samaranayake LP, MacFarlane TW. The adhesion of the yeast Candida albicans to epithelial cells of human origin in vitro. Arch Oral Biol 1981; 26: 815-20.

11 Henriques M, Azeredo J, Oliveira R. Candida species adhesion to oral epithelium: factors involved and experimental methodology used. Crit Rev Microbiol 2006; 32: 217-26.

12 Li X, Yan Z, Xu J. Quantitative variation of biofilms among strains in natural populations of Candida albicans. Microbiology 2003; 149: 353-62.

13 Henriques M, Azeredo J, Oliveira R. Candida albicans and Candida dubliniensis: comparison of biofilm formation in terms of biomass and activity. Br J Biomed Sci 2006; 63: 5-11.

14 Bizerra FC, Nakamura CV, Poersch $\mathrm{C}$ et al. Characteristics of biofilm formation by Candida tropicalis and antifungal resistance. FEMS Yeast Res 2008; 8: 442-50.

15 Silva GM, Silveira FR, Pires Mde MF. Adherence to HeLa cells, typing by killer toxins and susceptibility to antifungal agents of Candida dubliniensis strains. Braz Oral Res 2007; 21: 87-91.

16 Taguti Irie MM, Consolaro ME, Aparecida Guedes T, Donatti L, Valéria Patussi E, Estivalet Svidzinski TI. A simplified technique for evaluating the adherence of yeasts to human vaginal epithelial cells. J Clin Lab Anal 2006; 20: 195-203.

17 Pacheco M, Pisa D, García-Gómez P, Carrasco L, Juarranz A. Attachment and entry of Candida famata in monocytes and epithelial cells. Microsc Res Tech 2007; 70: 975-86.

18 Polacheck I, Antman A, Barth I, Sagi E, Giloh H. Adherence of Candida albicans to epithelial cells: studies using fluorescently labelled yeasts and flow cytometry. Microbiology 1995; 141: 1523-33.

19 King RD, Lee JC, Morris AL. Adherence of Candida albicans and other Candida species to mucosal epithelial cells. Infect Immun 1980; 27: 667-74.

20 Borg-von Zepelin M, Wagner T. Fluorescence assay for the detection of adherent Candida yeasts to target cells in microtest plates. Mycoses 1995; 38: 339-47.

21 Stepanovic S, Vukovic D, Dakic I, Savic B, Svabic-Vlahovic M. A modified microtiter-plate test for quantification of staphylococcal biofilm formation. J Microbiol Methods 2000; 40: 175-9.

22 Miyauchi M, Giummelly P, Yazawa S, Okawa Y. Adhesion of Candida albicans to HeLa cells: studies using polystyrene beads. Biol Pharm Bull 2007; 30: 588-90. 
23 Kimura LH, Pearsall NN. Adherence of Candida albicans to human buccal epithelial cells. Infect Immun 1978; 21: 64-8.

24 Kennedy MJ, Sandin RL. Influence of growth conditions on Candida albicans adhesion, hydrophobicity and cell wall ultrastructure. J Med Vet Mycol 1988; 26: 79-92.

25 Lee $\mathrm{KH}$, Yoon MS, Chun WH. The effects of monoclonal antibodies against iC3b receptors in mice with experimentally induced disseminated candidiasis. Immunology 1997; 92: 104-10.

26 Tamura NK, Gasparetto A, Svidzinski TI. Evaluation of the adherence of Candida species to urinary catheters. Mycopathologia 2003; 156: 269-72.

27 Li L, Redding S, Dongari-Bagtzoglou A. Candida glabrata: an emerging oral opportunistic pathogen. J Dent Res 2007; 86: 204-15.
28 Ghannoum MA. Potential role of phospholipases in virulence and fungal pathogenesis. Clin Microbiol Rev 2000; 13: 122-43.

29 Biasoli MS, Tosello ME, Magaró HM. Adherence of Candida strains isolated from the human gastrointestinal tract. Mycoses 2002; 45: 465-9.

30 Li L, Kashleva H, Dongari-Bagtzoglou A. Cytotoxic and cytokine inducing properties of Candida glabrata in single and mixed oral infection models. Microb Pathog 2007; 42: 138-47.

31 Shin JH, Kee SJ, Shin MG et al. Biofilm production by isolates of Candida species recovered from nonneutropenic patients: comparison of bloodstream isolates with isolates from other sources. J Clin Microbiol 2002; 40: 1244-8.

32 Zaugg C, Borg-Von Zepelin M, Reichard U, Sanglard D, Monod M. Secreted aspartic proteinase family of Candida tropicalis. Infect Immun 2001; 69: 405-12. 